\title{
Central-Local Relations: Recentralization and Environmental Governance in China
}

\author{
Genia Kostka* and Jonas Nahm ${ }^{\dagger}$
}

\begin{abstract}
Recent literature on environmental governance in China frequently ascribes blame for China's environmental problems to sub-national governments' lax environmental enforcement. Such research implicitly assumes that more central control would lead to better results but, as yet, the role of the centre in environmental governance remains underresearched. In the context of the current phase of recentralization, this article studies central and local interests, capacities and interactions across policy issues and government agencies. By "bringing the centre back" into the study of central-local relations in China, we examine both where such recentralization has in fact occurred and whether such recentralization efforts have improved environmental outcomes. We argue that centralization does not improve outcomes in every case. Further, central and local levels of governance are not as different as they might seem. Indeed, there are significant areas of overlapping interests and similar patterns of behaviour, both positive (enforcement) and negative (shirking), between central and local administrations. The results draw an empirically and theoretically rich picture of centrallocal relations that highlights the innate complexity of China's environmental governance patterns during the current phase of recentralization.
\end{abstract}

Keywords: central-local relations; environmental governance; China; pollution; recentralization

Since assuming office in 2012, Xi Jinping has consolidated power around him and implemented a raft of policies that have recentralized decision-making and strengthened central control. $\mathrm{Xi}$ has promoted wide-ranging anti-corruption pushes, strengthened his position by elevating himself as the "core leader" (hexin lingdao 核心领导) of the Chinese Communist Party (CCP), and asserted much greater control over economic policy than his two immediate predecessors. ${ }^{1}$

* Free University of Berlin. Email: g.kostka@fu-berlin.de

† Johns Hopkins University. Email: jnahm@jhu.edu. (corresponding author).

1 Brødsgaard 2015. 
Under Xi's leadership, China has entered a new phase of a longstanding cyclical pattern of "letting go" and "tightening up" ( fang/shou 放/收) that has characterized administrative reforms in China. ${ }^{2}$ In this phase of tightening up, the power balance between central and local governments has been tipped decisively in the centre's favour as Xi has removed powers and discretion from local governments, introduced new monitoring and sanctioning practices, and signalled a zero tolerance approach to non-compliance with central directives by sending thousands of local officials to prison. ${ }^{3}$ In addition, facing a range of immense political challenges, including a slowing economy, increasing social unrest and - the subject of this special section - unprecedented environmental degradation, China's central leadership has responded with an ambitious effort to recentralize administrative control, improve government accountability and stamp out corruption at all levels of government.

The question that arises is whether and to what extent the current phase of political recentralization is affecting environmental governance practices in China. Among scholars of environmental governance in China, there has been a consensus that China's decentralized administrative structure - designed to create incentives for implementing national growth-oriented mandates - has been ill-suited to address the nation's growing environmental challenges. ${ }^{4}$ Even when the centre has written good environmental laws, China's fiscal structure and cadre performance evaluation system have provided incentives for poor regulatory enforcement, delayed policy implementation, and widespread shirking of environmental laws at sub-national levels. Responsibility for the resulting "implementation gap" in environmental governance has been assigned to sub-national governments, which have prioritized economic over environmental goals. Existing literature on central-local relations in environmental governance has consequently focused on sub-national governments in their search for solutions to China's environmental governance problems. ${ }^{5}$

In the context of the current phase of political recentralization, this special section revisits central-local relations and their relevance in environmental governance in China. If local incentives are indeed to blame for China's poor record on environmental regulation, does increased central control improve governance outcomes? By "bringing the centre back in," the contributions to this collection examine both where such recentralization has in fact occurred and whether such recentralization efforts have indeed improved environmental governance patterns in China. As such, this special section seeks to advance theorizing about the circumstances under which different central-local relations lead to improved environmental governance. Building on rich empirical data across a spectrum of environmental policy issues and industrial sectors, the articles draw a more

2 On cyclical reforms and the "fang/shou" cycle, see for instance Baum 1996; He 1996.

3 Donaldson 2016, 105-137.

4 Mol and Carter 2006; Qi et al. 2008; Kostka and Mol 2013; Ran 2013; Qi and Zhang 2014.

5 Ran 2013; Kostka 2014. 
complex picture of China's environmental governance patterns during the current phase of recentralization.

Three common patterns emerge. First, despite Beijing's efforts to recentralize control, local governments differ with respect to their interests, efforts and capacity to foster good environmental outcomes. Hence, recentralization efforts have, to date, not fully upended existing local autonomy and the associated governance issues long identified in the literature. Second, the focus on central-local linkages and the study of local government responses to recentralization efforts point to a rise in new governance mechanisms and new constellations of actors. Agents critical to improving environmental outcomes are increasingly found beyond the traditional central-local dichotomy and rely on new horizontal linkages with firms, civil society and government agencies. These linkages have been enacted without resulting in a "hollowing out of the state." At the same time, the strengthening of vertical linkages between the Ministry of Environmental Protection and new local enforcement agencies have made it harder to fabricate information about local conditions and created new obstacles for those shirking environmental responsibilities.

Finally and most importantly, the contributions to this collection show that political recentralization, where it has indeed occurred, has not led to improved environmental governance in every case. Existing studies on central-local relations in environmental governance have often assumed that the centre's good intentions are thwarted by local governments acting on the basis of economic incentives. Yet, the articles in this special section query this assumption; we find significant variation in the centre's interest and ability to utilize recentralization for better environmental performance. The remainder of this introduction highlights these contributions.

\section{Local Autonomy under Central Control}

Local governments in China are important agents in environmental governance as they have considerable "room for manoeuvre" in China's regionally decentralized authoritarian system. ${ }^{7}$ Within this decentralized governance structure, the central government has historically exerted top-down control over the appointment and promotion of sub-national officials. At the same time, however, much of the business of government has been delegated to sub-national levels, which are responsible for providing public services, enforcing laws and regulations and implementing national legislation. ${ }^{8}$

The combination of central government control over officials' careers and local responsibility for implementing high-priority mandates ${ }^{9}$ has created tournament-like regional competition among local officials regarding performance. ${ }^{10}$ Advocates of

6 Rhodes 1994.

7 Landry 2008; Xu 2011; Harrison and Kostka, 2014.

8 Xu 2011; Heberer and Schubert 2012.

9 Birney 2014.

$10 \mathrm{Xu} 2011$. 
decentralized governance have long maintained that such inter-jurisdictional competition makes governments more accountable, responsive and efficient, ${ }^{11}$ and that local governments are better informed, can work most ably with civil society and produce synergies in public goods provision, ${ }^{12}$ and are effectively held to account through informal mechanisms due to their integration into the local community. ${ }^{13}$ However, political economists have suggested that tournament systems may break down when sub-national officials are responsible for multiple tasks. ${ }^{14}$ Currently, cadres receive a long list of high-priority and binding targets. Unless these competing policy priorities can be incorporated into a single, comprehensive index, promotion-oriented officials will engage in "selective implementation" of national initiatives and focus their efforts on what they perceive to be the implicit priorities of their superiors. ${ }^{15}$ This logic helps to explain why local officials continue to prioritize economic growth over environmental protection.

In this context, it is no surprise that China's decentralized governance structure has provided poor incentives for environmental policy implementation and regulatory enforcement. Yet, despite Beijing's efforts to streamline and centralize environmental governance, the contributions to this special section offer a finegrained view of continued variation in environmental governance among local jurisdictions. They show that even as the Xi administration attempts to recentralize environmental governance, local governments remain a heterogeneous group, as motivations, capacities and constraints continue to differ significantly across and within local governments, as well as across policy areas.

First, there are continuing differences in interests and capacities for environmental policymaking and enforcement across localities. As frequently stressed in the literature, decentralization has offered a space for some localities to move ahead and improve local environmental governance outcomes, while others have lagged behind. Even as the centre pays closer attention to the enforcement of environmental regulation and seeks to discipline laggards, compliance remains patchy and continues to display large regional variation. Best practices, as one finds in the case of Guangdong, are not automatically replicated in other parts of the country.

As Benjamin van Rooij, Zhu Qiaoqiao, Li Na and Wang Qiliang document in their detailed analysis of the enforcement of pollution regulation over time and across localities, increased central control has not always resulted in a re-prioritization of tasks such that environmental interests trump economic priorities when the two are in conflict. ${ }^{16}$ Van Rooij et al. show that in richer localities, where economic interests and environmental concerns are more likely to overlap and more resources are available for enforcement, localities have responded to

11 Tiebout 1956; Weingast 1995; Oates 1999; Jin, Qian and Weingast 2005.

12 Ostrom 1996; Lam 1997; Tendler 1997.

13 Tsai 2007. For a more detailed discussion on the pros and cons of centralized versus decentralized governance systems, see Balme and Qi 2014.

14 Holmstrom and Milgrom 1991.

15 O'Brien and Li 1999; Li and Zhou 2005; Guo 2007; Minzner 2009.

16 van Rooij et al., 2017 (this issue). 
central government control with improved regulation. On the other hand, changes to bureaucratic discretion through the introduction of minimum sanction amounts, the use of central government enforcement campaigns, and the establishment of branch offices of the national State Environmental Protection Agency (SEPA) to oversee environmental law enforcement have had little effect in poorer jurisdictions, where economic interests continue to outweigh environmental concerns. ${ }^{17}$ Higher levels of off-budget revenues from land leasing in more developed localities provide additional financial capacity to respond to central government mandates and improve environmental outcomes. ${ }^{18}$ In short, political recentralization alone has had a limited impact when local interests and enforcement capacity are hindered by the lack of local financial resources.

Second, local governments in China continue to display differences in interests and their capacity for environmental governance within local administrations. Under increasing pressure to meet environmental targets and improve outcomes, local officials engage in blame-shifting, as Party organizations try to deflect blame and assign responsibility for the regulatory failure to other local institutions. As Ran Ran argues, ${ }^{19}$ the effects of upgrading environmental indicators to "hard" targets with veto power in the performance evaluation system are not always salutary. Rather than offering incentives to improve performance, hard targets have also made blame-shifting among local officials more pervasive. Local Party cadres concerned about promotion because of a failure to meet environmental targets are likely to point the finger at local environmental protection bureaus (EPBs), which have limited authority and financial resources and are thus easy targets in the "chain of blame" in China's broader environmental governance system. ${ }^{20}$

Third, the contributions to this special section show that increased political recentralization has not harmonized governance outcomes across environmental policy areas. As discussed in the literature, the degree of local discretion in China's decentralized system of governance is primarily dependent on the degree of urgency and the scope of a particular policy. ${ }^{21}$ The centre, according to this view, is more likely to get involved in urgent cases that have a broad policy scope. Some policy areas such as climate change, which are inherently complex and carry significant scientific and policy uncertainty, might be better centrally governed, whereas policy areas such as waste water or soil management are best governed in a decentralized way. ${ }^{22}$ The articles in this special section confirm such views, and document that the visibility of environmental governance issues and the economic impact of addressing them affect central-local relations differently across different policy areas. Examining air pollution control in Hebei

19 Ran 2017 (this issue).

20 Ibid.

21 Donaldson 2016.

22 Balme and Qi 2014. 
province, Christine Wong and Valerie Karplus show that for highly visible issues, localities are subject to a high degree of central steering (and funding) ${ }^{23}$. For less visible issues, such as soil and water pollution, where public pressure is presumably less intense and there is less urgency to act, the centre continues to tolerate far greater local discretion. Kyong Shin, using the case of the Sanjiangyuan National-Level Natural Preservation Area, a peripheral locality far away from the political centre and national attention, finds significant local discretion to experiment with new climate policy and governance methods. ${ }^{24}$ Central authorities play a key role in initiating climate change strategies and encourage policy innovation by combining decentralized experimentation with ad hoc central intervention. ${ }^{25}$ Other findings here also suggest that the dynamic of intrajurisdictional competition continues to suffer from traditional collective action problems: among local officials, the incentives for shirking are greater for diffuse sources of pollution, such as air pollution, which are less easily attributed to individual sources and thus offer more cover for free-riding. Environmental issues that have local causes that are easily identified are more likely to receive local attention. $^{26}$

Finally, the contributions to this collection document variations in economic cost required to meet environmental governance targets and their role in driving variations across policy issues. In classic cases of green industrial policies for renewable energy sectors, where environmental and economic goals overlap, Jonas Nahm documents enthusiasm on the part of localities to respond to central mandates, even if central mandates are vague and not tied to specific enforcement mechanisms. ${ }^{27}$ Where pollution control directly conflicts with the economic imperative, Zhang documents the need for highly resource-intensive central enforcement programmes to ensure local compliance. ${ }^{28}$

\section{Innovative Governance Mechanisms and New Constellations of Actors}

The articles included in this special section collectively show evidence of an increasingly centralized governance system in China in which local governments adjust their priorities in response to hardened requirements and incentives coming from the centre. In this context, a focus solely on the motivations, capacities and constraints at the local level is insufficient to understand changes in environmental governance practices. The contributions document the emergence of new environmental governance mechanisms and new constellations of actors as a consequence of and in response to centralized policies, stricter enforcement, novel incentives from Beijing and competition between sub-national officials.

23 Wong and Karplus 2017 (this issue).

24 Shin 2017 (this issue).

25 Heilmann 2008.

26 Lora-Wainwright 2013; Shin 2017 (this issue).

27 Nahm 2017 (this issue).

28 Zhang 2017 (this issue). 
A number of innovative governance mechanisms have emerged to improve the traditional system of horizontal and vertical linkages and hierarchies (tiao-kuai 条块). First, the current phase of recentralization has witnessed the rise of new horizontal linkages across government agencies and civil society to facilitate joint problem-solving and coordination among government bodies and non-governmental stakeholders. For example, focusing on clean energy industry development in Baoding and environmental management in the Sanjiangyuan National-Level Natural Preservation Area, Shin identifies community-driven governance practices that connect actors from the public and private sectors, as well as civil society. These professional communities engage in collective learning, joint problem-solving and collective social sanctioning to meet or, in some cases, even modify central policy targets, thereby blurring the boundaries between government, business and civil society. While such community-driven governance practices resemble broader patterns of bottom-up experimental policymaking in China, ${ }^{29}$ this research shows that such experimentation also occurs in response to changes in incentives and policies at the central level. Interestingly, the centre has acted as a bridge of sorts that connects actors from civil society and the private sector with their counterparts in local government administrations..$^{30}$

Alliances that form bridges across bureaucracies are also crucial. Bruce Gilley emphasizes the role of horizontal administrative networks within local governments in improving environmental governance in response to central government signals. ${ }^{31}$ In the case of Guangzhou, the centre's emphasis on sustainable urban development met with the emergence of cross-agency administrative networks to address mitigation of greenhouse gases and sustainable economic development. The case study reveals how intra-government networks can enable the development of comprehensive and integrated local policy approaches.

Recentralization has also been accompanied by a strengthening of vertical linkages between central agencies and the location of enforcement. The articles in this special section by Zhang, Shin, and Van Rooij et al. point to the role of new institutions (both formal and informal) in bridging divides across levels of government. To improve the enforcement of pollution regulation, for instance, the Ministry of Environmental Protection (MEP, prior to 2008 the State Environmental Protection Agency, SEPA) established six regional supervision centres in 2006 to improve environmental law enforcement. To create a vertical line of control from central agencies to the location of enforcement at sub-national levels of government, all branch offices are directly funded and controlled by the centre. Zhang finds that the direct leadership of the MEP - although highly costly - has indeed curbed the falsification of pollution data at the local level and deterred enforcement violations. Despite such innovations, however, Van Rooij et al. nevertheless find differences in enforcement across richer urbanized areas and poorer

31 Gilley 2017 (this issue). 
inland provinces in China, which suggests that institutional improvements alone are unable to close the implementation gap.

Second, the articles document new entrepreneurial activities of both traditional (government) and non-traditional actors (such as the private sector, media and NGOs) who strategically utilize the political hierarchy to advance environmental goals. In a study of environmental compliance of central state-owned enterprises (SOEs), Sarah Eaton and Genia Kostka find growing numbers of bureaucratic entrepreneurs within the environmental government administration. ${ }^{32}$ Centrally owned SOEs are prone to shirking environmental regulation due to the central government's protectionism and the weak enforcement capacity of the environmental bureaucracy. However, entrepreneurial officials at both central and local levels have used the courts to hold SOEs accountable, have frozen offenders' bank accounts, and have creatively employed industrial policy tools to punish polluters (e.g. by reducing subsidies and issuing fines). Although such creative entrepreneurial actions against SOEs are not a substitute for environmental enforcement capacity, Eaton and Kostka remind us that weaknesses in formal institutions can to some extent be offset by the grit and determination of bureaucratic entrepreneurs. ${ }^{33}$

Such entrepreneurial initiatives to improve environmental governance are not only limited to the bureaucracy. Nahm shows that the development of competitive renewable energy sectors in China has relied on the strategic repurposing of industrial policies at the hands of entrepreneurial firms. ${ }^{34}$ Utilizing central government subsidies connected to indigenous innovation goals of encouraging autonomous domestic technology development, China's wind and solar firms have instead continued to collaborate with global partners. In so doing, they corrected shortcomings in the centre's narrow and nationalistic innovation policy and successfully inserted themselves in global wind and solar supply chains in ways that government planners had not anticipated. Particularly when economic and environmental goals overlap, as in the case of clean energy industries, such "room for manoeuvre" for private firms can lead to outcomes superior to those achieved in a strict command-and-control environment.

Beyond public and private entrepreneurs, the articles presented in this special section also highlight the rising importance of media and NGOs as actors in environmental governance. Eaton and Kostka discuss how media and internet platforms are increasingly used to name and shame polluters. ${ }^{35}$ For example, in Lanzhou, local government officials made savvy use of media power to leverage the force of public pressure directly on polluting state firms. NGOs have also started to publish real-time figures on air and water emissions on internet platforms and even created pollution-monitoring applications for mobile phones. These findings support

\footnotetext{
32 Eaton and Kostka 2017 (this issue).

33 Ibid.

34 Nahm 2017 (this issue).

35 Eaton and Kostka 2017 (this issue).
} 
existing studies that stress the arrival of new actors in environmental governance in China, such as judges, prosecutors, NGOs and Chinese citizens. ${ }^{36}$

\section{Recentralization Trends and Policy Outcomes}

China's environmental governance has undergone a pronounced recentralization over the past decade. Chinese leaders have made serious efforts to draw policymaking, implementation and oversight powers back to Beijing, especially since Xi Jinping's rise to power. The bold reform programme unveiled at the third plenary session of the 18th Central Committee in November 2013 - the "Decision on Some Major Issues Concerning Comprehensively Deepening the Reform" - calls for the "strictest possible rules to protect the ecological system" in the name of building an "ecological civilization." 37 The document outlines central leaders' plans to use more "sticks" in environmental protection, such as an increased use of criminal sanctions against polluters and the introduction of a "lifelong responsibility system" for government officials that would penalize officials with a poor track record of environmental protection. It also seeks to improve monitoring mechanisms, for instance by strengthening the collection and publication of environmental data and by conducting natural resource audits when senior officials leave their positions.

The contributions to this special section show how the central government's role in environmental protection has grown in importance in recent years. Van Rooij et al. detail the ways in which top-down enforcement has become tighter in China. A number of "centralizing trends" - including the introduction of stricter national environmental laws and sanctions, the use of binding environmental targets for local leaders, the reliance on nationwide central enforcement campaigns, and the introduction of a centralized verification programme of local emission data - have spurred stronger enforcement at the local level. The central government has also strengthened the institutions of environmental governance by increasing investment in environmental protection, which allows for the expansion of EPB human resources at the local level. In their case study of Hebei province, Wong and Karplus demonstrate that the central government's tying of financial transfers to the implementation of the Action Plan for Air Pollution Prevention and Control (APAP) initiative has proven to be an effective tactic in the context of immense financial pressures faced by local governments. ${ }^{38}$ They find that sub-national governments are, in fact, becoming more dependent on the centre at the moment. Beijing has also committed to generating more trustworthy information through an increased use of online monitoring satellite and GPS data, although there remains resistance to developing independent monitoring capacities. ${ }^{39}$

36 Mertha 2009; Teets and Hurst 2014; Van Rooij, Stern, and Fürst 2016; Shin 2017 (this issue).

37 Decision on Some Major Issues Concerning Comprehensively Deepening the Reform 2013.

38 Wong and Karplus 2017 (this issue)

39 Kostka 2016; Zhang 2017 (this issue). 
Although recentralization has the potential to improve environmental policy outcomes - by overcoming institutional fragmentation and weak incentives in China's decentralized system - this alone will not lead to stronger environmental governance. Two obstacles remain particularly salient. First, the centre requires sufficient, accurate information in order to design good policy, yet unreliable data from sub-national units have created a persistent bottleneck in China's command-and-control approach. Second, there is a need for an even stronger political commitment from the centre to prioritize environmental protection. Both issues have been taken for granted in much of the existing literature on central-local relations. The research findings in this collection show that there is significant variation in the centre's motivation and ability to utilize recentralization to achieve better environmental governance.

First, recentralization has little effect if the centre has no real interest in or intention of improving environmental outcomes. Central government control does not improve environmental governance, for instance, when the centre continues to prioritize economic goals over environmental targets, even in cases where there is central enforcement power over environmental regulation. In a study of pollution enforcement among central SOEs, Eaton and Kostka find that even when the centre directly oversees state enterprises, the shirking of pollution regulations is implicitly tolerated in the pursuit of better economic results. ${ }^{40}$ Such "central protectionism" of central SOEs often coincides with local protectionism; when China's State-owned Assets Supervision and Administration Commission (SASAC) tacitly encourages its firms to prioritize the attainment of traditional industrial policy goals (scale expansion and profitability), local governments are often complicit in the SOEs' environmental misdeeds. Eaton and Kostka's findings suggest that recentralization is, at best, a necessary condition for improved environmental governance but is by no means sufficient. When faced with trade-offs between environmental protection and growth, central officials are still likely to pick the latter.

The recentralization of environmental enforcement also complicates matters for a central leadership accustomed to shifting the blame for poor environmental outcomes to sub-national officials. Ran Ran documents how central Party leaders frequently lay the blame on local governments for the gap between environmental policies and implementation outcomes. ${ }^{41}$ In so doing, Ran argues, the centre effectively diverts attention from Beijing's role in precipitating China's environmental crisis and positions itself as leading the fight for environmental protection against wayward local governments. Such blame-shifting is harder to do when the centre has the authority to act but ultimately fails to do so, as in the case of central SOEs described by Eaton and Kostka. Ran's study reminds us that maintaining the implementation gap - often portrayed as an unintended consequence of an institutional structure designed to spur economic growth - 
may sometimes be useful for central officials (e.g. by maintaining hegemony), particularly when environmental problems prove difficult to solve. Both Eaton and Kostka's findings on central SOEs and Ran's work on environmental blame-shifting caution against the claim that China's central officials are more motivated than sub-national governments in addressing environmental issues.

Second, recentralization may not yield improved environmental governance outcomes when the centre has poor information. Worse yet, recentralization can lead to poor information or block high-quality information. One of the key arguments in favour of decentralizing governance has been to bring the locus of decision-making closer to the location of information about local conditions and preferences. ${ }^{42}$ Shin's study of horizontal linkages to civil society makes a strong case for the importance of joint problem-solving at the local level, tailored to local conditions, constraints and capabilities. ${ }^{43}$ It is unclear whether such horizontal linkages are compatible with strong central control. Moreover, as Nahm's research on the development of China's wind and solar sectors documents, the centre may also have poor information on conditions in the global economy. ${ }^{44}$ In renewable energy sectors, the implementation gap opened a space for private sector experimentation, in which firms were able to repurpose government policies to take advantage of opportunities in global supply chains disregarded by central government policies. Beijing has fashioned much of its industrial policies on the far more centralized East Asian developmental states. ${ }^{45}$ In China's wind and solar sectors, however, such centralization would have prevented local experimentation from serving as a corrective to the central government's narrow indigenous innovation goals. ${ }^{46}$

Third, even when the centre has an interest and sufficient information to act, central involvement does not lead to better outcomes when its policies are poorly designed and administered. Wong and Karplus's study on Hebei shows how the central government provides both detailed direction to local governments and significant funding, yet resources are sometimes not put to good use because of government capacity constraints..$^{47}$ In particular, China's top-down approach is not supported by adequate personnel allocations across different levels of governments to deliver the central government's ambitions. Beijing also continues to struggle with getting the incentives right. Political steering through mandatory targets often fails because of conflicting incentive structures (e.g. conflicting directives due to fragmentation at the centre), ${ }^{48}$ ineffective punishments and sanctions (e.g. "affordability of fines" for firms), ${ }^{49}$ and a lack of promotional

46 Nahm and Steinfeld 2014; Nahm 2017 (this issue).

47 Wong and Karplus 2017 (this issue).

48 Ran 2013.

49 Eaton and Kostka; Van Rooij et al. 2017 (this issue). 
opportunities..$^{50}$ As Wong and Karplus show, top-down mandates frequently negatively affect short-term growth, as well as social and economic stability; local authorities are therefore reluctant to carry out their delegated environmental responsibilities. Finally, China's reliance on command-and-control-based instruments and micromanagement leaves limited room for market-based approaches.

Despite the centre's efforts to wring more accurate information from the environmental governance system, stubborn obstacles remain. Zhang examines MEP's major effort to improve the centre's monitoring and verification capacities. ${ }^{51} \mathrm{Her}$ study focuses on a centrally imposed and executed verification programme of locally reported pollution data. She finds that although China's recent pollution verification programme has reduced the reporting of false data, significant challenges remain. In its current form, verification based on frequent inspection visits is highly resource-intensive and lacks external oversight and public participation. The verification programme has handed extensive discretionary power to the MEP and its regional supervision centres, which they have not used consistently across regions to improve data quality. While successful at reining in data falsification, their focus on curbing the overreporting of emissions reductions through spot checks has not created incentives for accurate data and continuous compliance. Local EPBs, meanwhile, have focused on providing data likely to pass muster with the MEP rather than genuinely improving systems for data collection and reporting.

Centralization has been able to improve individual issues of concern, as in the case of pollution data verification, but it has not fundamentally resolved problems in environmental governance in China. In stark contrast to the common perception of China's central government as a behemoth, the centre lacks sufficient administrative enforcement and monitoring capacities. ${ }^{52}$ The centre is in fact quite small in relative terms: China's administrative structure is like a dinosaur with a tiny brain and a big body. Given these constraints, some environmental areas receive little guidance from the centre and are managed through "ad hoc-driven processes," such as campaigns and ad hoc coalitions without the creation of comprehensive long-term structures. ${ }^{53}$ For instance, restructuring efforts that aim to move Chinese firms up the value chain are extremely difficult for localities to manage, and local officials often feel that the support they receive from the upper levels of government is insufficient. The result is weak enforcement capacities that give rise to both local protectionism ${ }^{54}$ and central protectionism. ${ }^{55}$ 


\section{Conclusion and Outlook}

Recent literature on environmental governance in China has provided important insights into the behaviour of local governments in China's decentralized administrative structure. A great deal of research has focused on the dominant influence of economic incentives on local officials and their unintended yet destructive consequences for environmental governance. The conventional wisdom emerging from such insights attributed much of the blame for lax environmental enforcement to local officials and implicitly assumed that more central control would lead to better results. Yet despite important advances in research on central-local relations, much work remains to be done to understand the role, interests and interactions of agencies across different government levels in shaping environmental governance outcomes in China. By focusing specifically on central-local relations during the current phase of recentralization in China, the contributions to this special section seek to fill this gap and advance our understanding of central and local administrations' roles and potentials in improving China's environmental record.

Over the past decade, Chinese leaders have made strong efforts to concentrate policymaking, implementation and oversight powers in Beijing. With regard to these centralizing trends under Xi Jinping, the research in this collection of articles shows that the results of the centre taking control of China's green transformation can indeed lead to improved environmental results. Increased attention and financial resources from the centre have made it possible to change the behaviour of local officials. Institutional changes and the strengthening of vertical linkages between local enforcement agencies and the Ministry of Environmental Protection have made it harder to falsify information about local conditions and created new obstacles for shirking behaviours. At the same time, however, recentralization is not a panacea. There is significant variation in the centre's interest and ability to use its powers to achieve better environmental governance across policy areas. And even if the centre is sufficiently motivated, it frequently lacks adequate information or chooses poor policy designs. In other words, centralization alone is not a silver bullet, and close attention needs to be paid to policies, capacities and interests at different levels of government.

The contributions to this collection remind us that central and local interests are not in all cases categorically pitted against one another, as is often assumed in the environmental governance literature as well as research on central-local relations more broadly. There are significant areas of overlapping interests and similar patterns of behaviour, both positive (enforcement) and negative (shirking), between central and local administrations. Particularly during the current phase of recentralization, central and local interests cannot be assumed but need themselves to be examined, through empirically rich analysis, across policy issues and government agencies. Although the findings presented here focus specifically on China's environmental governance, there is much reason to believe that these lessons apply across governance areas shaped heavily by centrallocal relations in China. 


\title{
Acknowledgements
}

We thank Ling Chen, Kyle Jaros, Alanna Krolikowski, Scott Moore, Timmons Roberts, Nick Smith, Edward Steinfeld and Da Zhang for the lively discussion and constructive feedback at the 2015 Brown University-Hertie School of Governance Workshop on Environmental Governance in China. We are grateful to the Brown University China Initiative for generously funding the workshop.

\section{Biographical notes}

Genia Kostka is professor of Chinese politics at the Free University of Berlin. Jonas Nahm is assistant professor of energy, resources, and environment at the School of Advanced International Studies at Johns Hopkins University in Washington, DC.

\begin{abstract}
摘要: 近来关于中国环境治理的文献经常将中国的环境问题归处于地方政 府松解的环保执法。这类研究其实是隐晦地假设越多的中央管控就能带来 越好的结果, 但是对中央政府在环境治理中所扮演的角色, 至今仍缺乏足够 的研究。在现阶段重新集权化的大背景下, 本文将梳理中央与地方的利益、 能力以及在政策问题和政府机构上的相互作用。通过 “将中央重新带回” 关 于中国中央-地方关系的研究中，我们将检视这种重新集权化实际上在哪些 地方发生, 以及这种重新集权化的努力是否改善了环保成效。我们认为集权 化并不能在每种情况下都改善环保成效。而且, 中央和地方层次的治理并不 像看上去那样迥然不同。事实上，在中央与地方行政部门间，不管是在积极 (即主动执法) 还是消极 (即推卸责任) 的方面, 都有很多重要领域存在利益重 叠, 也有相似的行为模式。我们的研究结果也在实证和理论两方面, 为中央一 地方关系勾画了一幅丰富充实的画面, 突出了当前重新集权化阶段下中国环 境治理模式中固有的复杂性。
\end{abstract}

关键词: 中央-地方关系; 环境治理; 中国; 污染; 重新集权化

\section{References}

Balme, Richard, and Ye Qi. 2014. "Multi-level governance and the environment: intergovernmental relations and innovation in environmental policy." Environmental Policy and Governance 24(3), 147-154.

Baum, Richard. 1996. Burying Mao: Chinese Politics in the Age of Deng Xiaoping. Princeton: Princeton University Press.

Birney, Mayling. 2014. "Decentralization and veiled corruption under China's 'rule of mandates'." World Development 53, 55-67.

Brødsgaard, Kjeld Erik. 2015. "Assessing the Fourth Plenum of the Chinese Communist Party: personnel management and corruption." Asia Policy 20(1), 30-37.

Decision on Major Issues Concerning Comprehensively Deepening Reforms (abridged version): http:// www.china.org.cn/china/third_plenary_session/2013-11/16/content_30620736_4.htm; Chinese version: http://news.xinhuanet.com/politics/2013-11/15/c_118164235.htm. Accessed 5 November 2016. 
Donaldson, John A. 2016. "China's administrative hierarchy: the balance of power and winners and losers within China's levels of government." In John Donaldson (ed.), Assessing the Balance of Power in Central-Local Relations in China. New York: Routledge, 105-137.

Eaton, Sarah, and Genia Kostka. 2017. "Central protectionism in China: the 'central SOE problem' in environmental governance." The China Quarterly, special section "Central-local relations and environmental governance in China."

Guo, Gang. 2007. "Retrospective economic accountability under authoritarianism evidence from China." Political Research Quarterly 60(3), 378-390.

Gilley, Bruce. 2017. "Local governance pathways to decarbonization in China and India." The China Quarterly, special section "Central-local relations and environmental governance in China."

Harrison, Tom, and Genia Kostka. 2014. "Balancing priorities, aligning interests: developing mitigation capacity in China and India." Comparative Political Studies 47(3), 450-480.

He, Baogang. 1996. "Dilemmas of pluralist development and democratization in China." Democratization 3(3), 287-305.

Heberer, Thomas, and Gunter Schubert. 2012. "County and township cadres as a strategic group. A new approach to political agency in China's local state.” Journal of Chinese Political Science 17(3), 221-249.

Heilmann, Sebastian. 2008. "From local experiments to national policy: the origins of China's distinctive policy process." The China Journal 59, 1-30.

Heilmann, Sebastian. 2009. "Maximum tinkering under uncertainty unorthodox lessons from China." Modern China 35(4), 450-462.

Holmstrom, Bengt, and Paul Milgrom. 1991. "Multitask principal-agent analyses: incentive contracts, asset ownership, and job design." Journal of Law, Economics, \& Organization 7, 24-52.

Jin, Hehui, Yingyi Qian and Barry Weingast. 2005. "Regional decentralization and fiscal incentives: federalism, Chinese style." Journal of Public Economics 89, 1719-42.

Kostka, Genia. 2014. "Barriers to the implementation of environmental policies at the local level in China." World Bank Policy Research Working Paper No. WPS 7016. Washington, DC: World Bank Group. http://documents.worldbank.org/curated/en/2014/08/20144757/barriers-implementation-environmentalpolicies-local-level-china.

Kostka, Genia. 2016. "Command without control: the case of China's environmental target system." Regulation \& Governance 10, 58-74.

Kostka, Genia, and Arthur P.J. Mol. 2013. "Implementation and participation in China's local environmental politics: challenges and innovations." Journal of Environmental Policy \& Planning 15(1), $3-16$.

Kostka, Genia, and Xiaofan Yu. 2015. "Career backgrounds of municipal Party secretaries in China: why do so few municipal Party secretaries rise from the county level?" Modern China 41(5), 467-505.

Lam, Wai Fung. 1997. "Institutional design of public agencies and coproduction: a study of irrigation associations in Taiwan." In Peter B. Evans (ed.), State-Society Synergy: Social Capital in Development. Berkeley: University of California Press, 1997, 11-40.

Li, Hongbin, and Li-An Zhou. 2005. "Political turnover and economic performance: the incentive role of personnel control in China." Journal of Public Economics 89(9), 1743-62.

Landry, Pierre F. 2008. Decentralized Authoritarianism in China. New York: Cambridge University Press.

Lora-Wainwright, Anna. 2013. "Introduction. Dying for development: pollution, illness and the limits of citizens' agency in China." The China Quarterly 214, 243-254.

Mei, Ciqi, and Margaret M. Pearson. 2014. "Killing a chicken to scare the monkeys? Deterrence failure and local defiance in China." The China Journal 72, 75-97.

Mertha, Andrew. 2009. "'Fragmented Authoritarianism 2.0': political pluralization in the Chinese policy process." The China Quarterly 200, 995-1012.

Minzner, Carl F. 2009. "Riots and cover-ups: counterproductive control of local agents in China." University of Pennsylvania Journal of International Law 31, 53-123. 
Mol, Arthur P.J., and Neil T. Carter. 2006. "China's environmental governance in transition." Environmental Politics 15(2), 149-170.

Nahm, Jonas. 2017. "Exploiting the implementation gap: policy divergence and industrial upgrading in China's wind and solar sectors." The China Quarterly, special section "Central-local relations and environmental governance in China."

Nahm, Jonas, and Edward S. Steinfeld. 2014. "Scale-up nation: China's specialization in innovative manufacturing." World Development 54, 288-300.

Oates, Wallace E. 1972. Fiscal Federalism. New York: Harcourt Brace Jovanovich.

Oates, Wallace E. 1999. “An essay on fiscal federalism.” Journal of Economic Literature 37(3), 1120-49.

O’Brien, Kevin J., and Lianjiang Li. 1999. "Selective policy implementation in rural China." Comparative Politics 31(2), 167-186.

Ostrom, Elinor. 1996. "Crossing the great divide: coproduction, synergy, and development." World Development 24(6), 1073-87.

Qi, Ye, Li Ma, Huanbo Zhang and Huimin Li. 2008. "Translating a global issue into local priority China's local government response to climate change." The Journal of Environment \& Development 17(4), 379-400.

Qi, Ye, and Lingyun Zhang. 2014. "Local environmental enforcement constrained by central-local relations in China." Environmental Policy and Governance 24(3), 216-232.

Ran, Ran. 2013. "Perverse incentive structure and policy implementation gap in China's local environmental politics.” Journal of Environmental Policy \& Planning 15(1), 17-39.

Ran, Ran. 2017. "Understanding blame politics in China's decentralized system of environmental governance: actors, strategies and context." The China Quarterly, special section "Central-local relations and environmental governance in China."

Rhodes, Rod A.W. 1994. "The hollowing out of the state: the changing nature of the public service in Britain." The Political Quarterly 65(2), 138-151.

Shin, Kyoung. 2017. "Neither centre nor local: community-driven experimentalist governance in China." The China Quarterly, special section "Central-local relations and environmental governance in China."

Steinfeld, Edward S. 2004. "China's shallow integration: networked production and the new challenges for late industrialization." World Development 32(11), 1971-87.

Teets, Jessica C., and William Hurst (eds.). 2014. Local Governance Innovation in China: Experimentation, Diffusion, and Defiance. New York: Routledge.

Tendler, Judith. 1997. Good Government in the Tropics. Baltimore: Johns Hopkins University Press.

Tiebout, Charles M. 1956. "A pure theory of local expenditures." The Journal of Political Economy 64 (5), 416-424.

Tsai, Lily L. 2007. Accountability without Democracy: Solidary Groups and Public Goods Provision in Rural China. Cambridge: Cambridge University Press.

Van Rooij, Benjamin, Rachel Stern and Kathinka Fürst. 2016. "The authoritarian logic of regulatory pluralism, understanding China's new environmental actors.” Regulation \& Governance 10(1), 3-13.

Van Rooij, Benjamin, Qiaoqiao Zhu, Li Na and Wang Qiliang. 2017. "Centralizing trends and pollution law enforcement in China." The China Quarterly, special section "Central-local relations and environmental governance in China."

Weingast, Barry R. 1995. "The economic role of political institutions: market-preserving federalism and economic development." Journal of Law, Economics, \& Organization 11(1), 1-31.

Wong, Christine, and Valerie J.Karplus. 2017. "China's war on air pollution: can existing governance structures support new ambitions?" The China Quarterly, special section "Central-local relations and environmental governance in China."

Xu, Chenggang. 2011. "The fundamental institutions of China's reforms and development." Journal of Economic Literature 49(4), 1076-1151.

Zhang, Xuehua. 2017. "Implementation of pollution control targets in China: has a centralized enforcement approach worked?" The China Quarterly, special section "Central-local relations and environmental governance in China." 